\title{
Fabric-based Strain Sensors for Measuring Movement in Wearable Telemonitoring Applications
}

\author{
C.D. Metcalf*\$ ${ }^{\S}$, S.R. Collie ${ }^{\dagger}$, A.W. Cranny ${ }^{\S}$, G. Hallett ${ }^{\natural}$, C. James ${ }^{\ddagger}$, J. Adams*, P.H. Chappell ${ }^{\S}$, \\ N.M. White ${ }^{\S}$ \& J.H. Burridge*
}

\begin{abstract}
* School of Health Sciences, University of Southampton, UK. Email: c.d.metcalf@soton.ac.uk; `School of Electronics \& Computer Science, University of Southampton; ${ }^{\dagger}$ AgResearch Limited, Christchurch, New Zealand; ${ }^{a}$ Southampton University Hospitals NHS Trust; ${ }^{\ddagger}$ Institute of Sound and Vibration Research, University of Southampton.
\end{abstract}

Keywords: Wearable, Smart Textiles, Joint Angle, Movement, Measurement.

\begin{abstract}
This paper summarises preliminary work comparing conductive yarns, knitting structures and yarn compositions in order to integrate smart sensor strips into a surrounding garment as a kinematic measurement tool. The conductive areas of the garment were to be used as a strain-sensitive material; ultimately measuring knee joint movement. In total, thirty sample fabrics were developed using conductive yarns; six of which were chosen to be tested for responsiveness during repeated strain. Preliminary tests showed good levels of responsiveness to strain and acceptable levels of recovery.
\end{abstract}

\section{Introduction}

Measurement of kinematic responses during activities of daily living can be used to assess functional ability, define impairment and target treatment, particularly in gait analysis [1]. Analysing movement in the controlled environment of a laboratory can generate data with high levels of reliability during clearly defined movements [2-4]. However, analysis of movement in such controlled environments provides only limited information to assist understanding of functional movement in a real environment, such as a person's home, in a gym or outdoors [2; 5]. Measuring movement in a real environment is problematic in terms of stability of data due to, for example, variation in sensor positions and changes in sensor output over time [6; 7]. In addition, needing (in some instances) to relocate bulky measurement systems (e.g. cameras for motion capture), is often unrealistic.

The objective of this study was to develop fabric-based strain sensors capable of measuring knee flexion/extension of patients with anterior cruciate ligament rupture. The strain sensors were designed to be integrated within a garment to be worn across the knee joint and measure knee joint movement during a functional activity. Several fabrics were tested to identify suitable compositions and integrated into surrounding garment.

\section{Method}

Thirty sample fabrics were produced on both a 12-gauge single-feed circular knitting machine and a 7-gauge Shima Seika SES122-S electronic v-bed knitting machine. Samples 01 - 18 were produced using the circular knitting machine and samples 19 - 30 were produced using the v-bed machine.

Samples were produced using several conductive yarns (stainless steel, silver coated nylon and Europa*), varying cover factors (a higher number indicates a tighter knit), and also knitting structures, surrounding non-conductive base yarns, blends and twists. Figure 1 shows a wool-based sample with silver coated nylon plated throughout. When stretched (see Figure 2), the resistance of the conductive fabric changes, causing a measurable response.

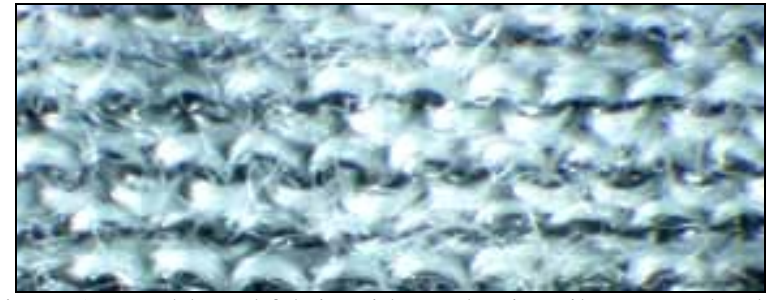

Figure 1: Wool-based fabric with conductive silver coated nylon filaments throughout.

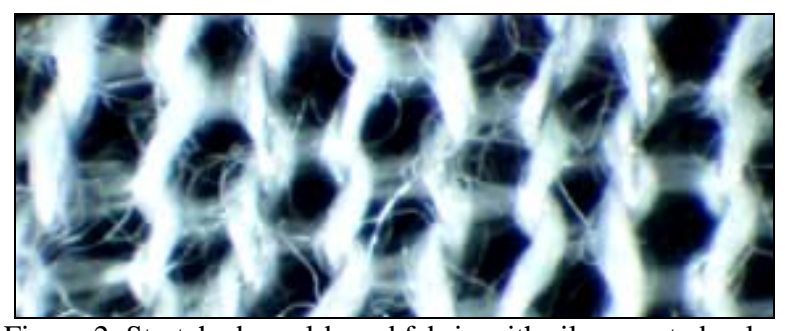

Figure 2: Stretched wool-based fabric with silver coated nylon filaments causing a measurable change in resistance.

Strip samples $(10 \mathrm{~cm} \times 1 \mathrm{~cm})$ were taken from each fabric for testing. A test rig (see Figure 3) was constructed to perform simple strain-resistance measurements, wherein each sample was clamped at one end and suspended from a rig and

\footnotetext{
* Europa yarn is a gill blend (teasing of the fibres) of $40 \%$ polyester, $40 \%$ copper sulphides and $20 \%$ stainless steel.
} 
weights were attached to the other end in $10 \mathrm{~g}$ increments. Each sample was tested during loading and unloading (0g $100 \mathrm{~g}-0 \mathrm{~g}$ ), while the electrical resistance was recorded (in ohms) using a Fluke 114 multimeter.

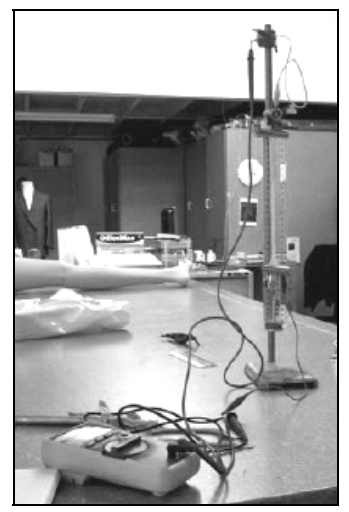

Figure 3: Test rig for measuring resistance of conductive fabric samples during weighted loading and unloading.

\section{Summary of Samples}

\begin{tabular}{|c|c|c|c|}
\hline No & CF & Yarns & Structure \\
\hline 01 & 1.20 & $\begin{array}{l}\text { Wool base (R50/2 tex) } \\
\text { SCN ( } 4.4 \text { tex) } \\
\text { Elastane }(4.4 \text { tex })\end{array}$ & $\begin{array}{l}\text { Plated } \\
\text { throughout } \\
(\mathrm{SJ})\end{array}$ \\
\hline 02 & 1.20 & $\begin{array}{l}\text { Wool base (R50/2 tex) } \\
\text { SCN ( } 4.4 \text { tex) } \\
\text { Elastane ( } 4.4 \text { tex) }\end{array}$ & $\begin{array}{l}1 \times 1 \text { plated } \\
\text { (SJ) as No. } 01\end{array}$ \\
\hline 03 & 1.20 & $\begin{array}{l}\text { Wool base (R50/2 tex) } \\
\text { SCN ( } 4.4 \text { tex) } \\
\text { Elastane }(4.4 \text { tex })\end{array}$ & $\begin{array}{l}2 \times 2 \text { plated } \\
(\mathrm{SJ}) \text { as No. } 01\end{array}$ \\
\hline 04 & 1.20 & $\begin{array}{l}\text { Wool base (R50/2 tex) } \\
\text { SCN ( } 4.4 \text { tex) } \\
\text { Elastane }(4.4 \text { tex) }\end{array}$ & $\begin{array}{l}4 \times 4 \text { plated } \\
(\mathrm{SJ}) \text { as No. } 01\end{array}$ \\
\hline 05 & 1.43 & $\begin{array}{l}\text { Wool base (R50/2 tex) } \\
\text { SCN ( } 4.4 \text { tex) } \\
\text { Elastane }(4.4 \text { tex) }\end{array}$ & $\begin{array}{l}\text { Plated } \\
\text { throughout } \\
(\mathrm{SJ})\end{array}$ \\
\hline 06 & 1.43 & $\begin{array}{l}\text { Wool base (R50/2 tex) } \\
\text { SCN ( } 4.4 \text { tex) } \\
\text { Elastane ( } 4.4 \text { tex) }\end{array}$ & $\begin{array}{l}1 \times 1 \text { plated } \\
\text { (SJ) as No. } 05\end{array}$ \\
\hline 07 & 1.43 & $\begin{array}{l}\text { Wool base (R50/2 tex) } \\
\text { SCN ( } 4.4 \text { tex) } \\
\text { Elastane }(4.4 \text { tex })\end{array}$ & $\begin{array}{l}\text { 2x2 plated } \\
\text { (SJ) as No. } 05\end{array}$ \\
\hline 08 & 1.43 & $\begin{array}{l}\text { Wool base (R50/2 tex) } \\
\text { SCN ( } 4.4 \text { tex) } \\
\text { Elastane }(4.4 \text { tex })\end{array}$ & $\begin{array}{l}4 \times 4 \text { plated } \\
(\mathrm{SJ}) \text { as No. } 05\end{array}$ \\
\hline 09 & 1.43 & $\begin{array}{l}\text { Spun polyester base (R74/2 tex) } \\
\text { SCN }(4.4 \text { tex }) \\
\text { Elastane }(4.4 \text { tex })\end{array}$ & Plain (SJ) \\
\hline 10 & 1.55 & $\begin{array}{l}\text { Spun polyester base (R74/2 tex) } \\
\text { SCN ( } 4.4 \text { tex) } \\
\text { Elastane }(4.4 \text { tex) }\end{array}$ & As No. 09 \\
\hline 11 & 1.74 & $\begin{array}{l}\text { Wool \& stainless steel blend (R100/2 } \\
\text { tex) } \\
\text { Elastane ( } 4.4 \text { tex) }\end{array}$ & Plain (SJ) \\
\hline 12 & 1.53 & $\begin{array}{l}\text { Wool \& stainless steel blend } \\
\text { (R100/2 tex) } \\
\text { Elastane ( } 4.4 \text { tex) }\end{array}$ & As No. 11 \\
\hline 13 & 1.43 & $\begin{array}{l}\text { Spun polyester base (R74/2 tex) } \\
\text { SCN }(4.4 \text { tex }) \\
2 \text { x Elastane }(4.4 \text { tex })\end{array}$ & Plain (SJ) \\
\hline
\end{tabular}

\begin{tabular}{|c|c|c|c|}
\hline No & $\mathbf{C F}$ & Yarns & Structure \\
\hline 14 & 1.25 & $\begin{array}{l}\text { Wool base (R50/2 tex) } \\
\text { SCN (4.4 tex) } \\
2 \text { x Elastane ( } 4.4 \text { tex) }\end{array}$ & $\begin{array}{l}\text { Plated } \\
\text { throughout } \\
\text { (SJ) }\end{array}$ \\
\hline 15 & 1.43 & $\begin{array}{l}\text { Spun polyester base (R74/2 tex) } \\
2 \text { x SCN }(4.4 \text { tex }) \\
\text { Elastane }(4.4 \text { tex })\end{array}$ & $\begin{array}{l}\text { Plain (SJ) as } \\
\text { No. } 13\end{array}$ \\
\hline 16 & 1.25 & $\begin{array}{l}\text { Wool base (R50/2 tex) } \\
2 \text { x SCN }(4.4 \text { tex) } \\
\text { Elastane }(4.4 \text { tex })\end{array}$ & $\begin{array}{l}\text { Plated } \\
\text { throughout } \\
\text { (SJ) as No. 14 }\end{array}$ \\
\hline 17 & 1.39 & $\begin{array}{l}2 \text { x Polyester twisted with } \\
\text { SCN (30 tex) } \\
\text { Elastane }(4.4 \text { tex) }\end{array}$ & Plain (SJ) \\
\hline 18 & 1.21 & $\begin{array}{l}\text { Europa (R50/2) } \\
\text { Elastane (4.4 tex) }\end{array}$ & Plain (SJ) \\
\hline 19 & NA & $\begin{array}{l}\text { Wool \& stainless steel blend } \\
\text { (R100/2 tex) } \\
\text { Elastane ( } 4.4 \text { tex) }\end{array}$ & Plain (RS) \\
\hline 20 & NA & $\begin{array}{l}\text { Wool base (R50/2 tex) } \\
\text { Stainless steel blend (R100/5 tex) } \\
\text { Elastane (4.4 tex) }\end{array}$ & $\begin{array}{l}\text { Plated } \\
\text { stainless steel } \\
\text { on relief (RS) }\end{array}$ \\
\hline 21 & NA & $\begin{array}{l}\text { Wool base (R50/2 tex) } \\
\text { Stainless steel blend (R100/5 tex) } \\
\text { Elastane ( } 4.4 \text { tex) }\end{array}$ & $\begin{array}{l}\text { Plated } \\
\text { stainless steel } \\
\text { on back (RS) }\end{array}$ \\
\hline 22 & 0.86 & $\begin{array}{l}\text { Wool base (R50/2 tex) } \\
\text { SCN (4.4 tex) } \\
\text { Elastane (4.4 tex) }\end{array}$ & $\begin{array}{l}\text { Two-wale CS } \\
\text { (SJ) }\end{array}$ \\
\hline 23 & 0.86 & $\begin{array}{l}\text { Wool base (R50/2 tex) } \\
\text { SCN (4.4 tex) } \\
\text { Elastane ( } 4.4 \text { tex) }\end{array}$ & $\begin{array}{l}\text { Four-wale CS } \\
\text { (SJ) }\end{array}$ \\
\hline 24 & 0.86 & $\begin{array}{l}\text { Wool base (R50/2 tex) } \\
\text { SCN (4.4 tex) } \\
\text { Elastane (4.4 tex) }\end{array}$ & $\begin{array}{l}\text { Eight-wale } \\
\text { CS (SJ) }\end{array}$ \\
\hline 25 & 1.33 & $\begin{array}{l}\text { Wool base (R50/2 tex) } \\
\text { SCN ( } 4.4 \text { tex) } \\
\text { Wrapped } 311 \text { turns per metre } \\
\text { Elastane ( } 4.4 \text { tex) }\end{array}$ & Plain (SJ) \\
\hline 26 & 1.33 & $\begin{array}{l}\text { Wool base (R50/2 tex) } \\
\text { SCN ( } 4.4 \text { tex) } \\
\text { Wrapped } 153 \text { turns per metre } \\
\text { Elastane ( } 4.4 \text { tex) }\end{array}$ & As No. 25 \\
\hline 27 & 0.83 & $\begin{array}{l}\text { Wool base (R50/2 tex) } \\
\text { SCN ( } 4.4 \text { tex) } \\
\text { Elastane (4.4 tex) }\end{array}$ & $\begin{array}{l}\text { As No. } 24 \\
\text { without } \\
\text { elastane in CS }\end{array}$ \\
\hline 28 & 0.86 & $\begin{array}{l}\text { Wool base (R50/2 tex) } \\
\text { SCN ( } 4.4 \text { tex) } \\
\text { Elastane (4.4 tex) }\end{array}$ & $\begin{array}{l}\text { As No. } 24 \\
\text { with } 1 / 2 \\
\text { courses } \\
\end{array}$ \\
\hline 29 & 0.83 & $\begin{array}{l}\text { Wool base (R50/2 tex) } \\
\text { SCN ( } 4.4 \text { tex) } \\
\text { Elastane (4.4 tex) }\end{array}$ & $\begin{array}{l}\text { As No. } 28 \\
\text { without } \\
\text { elastane in CS }\end{array}$ \\
\hline 30 & $\begin{array}{l}0.75 \\
\text { (est.) }\end{array}$ & $\begin{array}{l}\text { Wool base (R50/2 tex) } \\
\text { SCN ( } 4.4 \text { tex)elastane ( } 4.4 \text { tex) }\end{array}$ & $\begin{array}{l}\text { As No. 28 } \\
\text { with longer } \\
\text { stitch length } \\
\text { in BS } \\
\end{array}$ \\
\hline
\end{tabular}

Table 1: Summary of samples; where $\mathrm{CF}=$ cover factor, $\mathrm{CS}=$ conductive strip, BS = base surrounding fabric and SCN = silvercoated nylon. Structures are denoted as SJ = single jersey and RS = relief structure. Numbers describing the structure indicate the change courses during fabric construction (i.e. $1 \times 1$ = one course base, 1 course conductive yarn).

Samples were produced in eight batches; each batch was tested and further iterations were developed. Using incremental designs, improvements to subsequent batches were made, based on results observed during testing. Each sample was tested for incremental loading and unloading using the test rig. Responsiveness to load was measured and recovery response offset was calculated as the average 
difference between the beginning of the loading cycle and the end $(0 \mathrm{~g})$, over three repeated cycles.

\section{Results}

Batches were developed to test the following assumptions:

- Batch 1 (samples 01 to 08) was a series of conductive strips based within a wool surrounding fabric, developed to give an initial baseline dataset;

- Batch 2 (samples 09 to 12) tested whether the orientation of the knit affected the recovery response of the sample and also tested polyester as an alternative base yarn, as well as a wool/stainless steel blend as an alternative conductive yarn;

- Batch 3 (samples 13 to 16) tested whether increasing the elastane or the amount of conductive yarn improved the deformation/recovery response of the fabric sample;

- Batch 4 (samples 17 to 19) tested two new conductive yarns and sample 19 tested a relief structure;

- Batch 5 (samples 20 and 21) used a plating technique on either side of the relief structure;

- Batch 6 (samples 22 to 24) tested a single jersey structure with conductive strips of various widths;

- Batch 7 (samples 25 to 26) tested two bespoke wrap-spun yarns produced by AgResearch;

- Batch 8 (samples 27 to 30) tested the affect of removing the elastane from the conductive strip and altering the structure of the surrounding fabric as a method of enhancing the recovery response and minimising the recovery offset of the samples.

From 30 initial samples, six showed a reasonable recovery response to the loading/unloading cycle and were tested further in both the course (crossways) and wale (lengthways) direction for repeated sensitivity to strain and levels of recovery response over three cycles. Figure 4 shows the response of a sample fabric cut in the wale direction under these conditions.

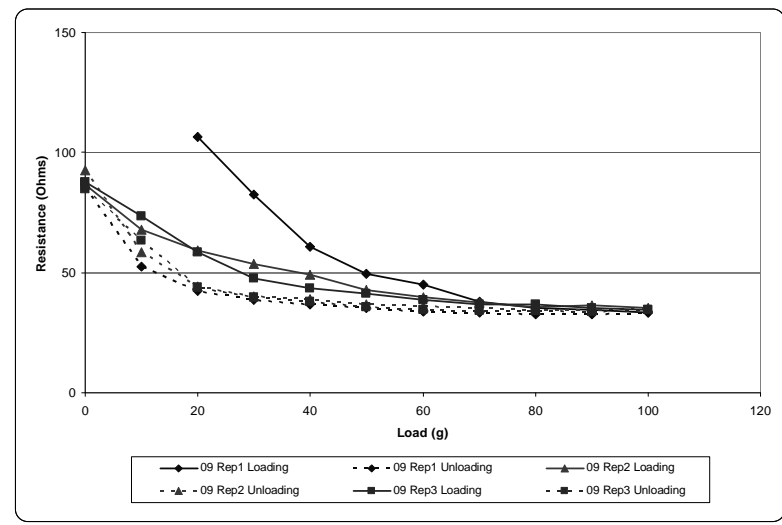

Figure 4: Sample 09 loading and unloading cycle response.

Sample 09 was shown to have the lowest hysteresis over the three loading/unloading cycles. It was observed that five out of the six samples cut in the wale direction and tested for repeated strain showed improved levels of recovery after an initial stretch response.

\begin{tabular}{|l|c|c|c|}
\hline No & Repeat & $\begin{array}{c}\text { Relative Recovery } \\
(\mathbf{\%})\end{array}$ & $\begin{array}{c}\text { Absolute Recovery } \\
\text { Offset }(\boldsymbol{\Omega})\end{array}$ \\
\hline $01(\mathrm{~W})$ & $1 / 2 / 3$ & $12.5 / 17.2 / 18.2$ & $0.4 / 0.5 / 0.6$ \\
\hline $05(\mathrm{~W})$ & $1 / 2 / 3$ & $27.3 / 24.0 / 11.5$ & $0.6 / 0.6 / 0.3$ \\
\hline $09(\mathrm{~W})$ & $1 / 2 / 3$ & $52.7 / 28.0 / 20.8$ & $1.2 / 0.7 / 0.5$ \\
\hline $10(\mathrm{~W})$ & $1 / 2 / 3$ & $29.2 / 21.4 / 7.1$ & $0.7 / 0.6 / 0.2$ \\
\hline $13(\mathrm{~W})$ & $1 / 2 / 3$ & $23.1 / 21.4 / 40.9$ & $0.3 / 0.3 / 0.9$ \\
\hline $14(\mathrm{~W})$ & $1 / 2 / 3$ & $46.2 / 16.7 / 28.6$ & $0.6 / 0.3 / 0.6$ \\
\hline $01(\mathrm{C})$ & $1 / 2 / 3$ & $60.3 / 9.0 / 24.7$ & $37.2 / 11.3 / 38.7$ \\
\hline $05(\mathrm{C})$ & $1 / 2 / 3$ & $45.8 / 21.5 / 3.5$ & $274 / 61.2 / 9.1$ \\
\hline $09(\mathrm{C})$ & $1 / 2 / 3$ & $28.5 / 10.2 / 5.9$ & $85.5 / 5.9 / 3.2$ \\
\hline $10(\mathrm{C})$ & $1 / 2 / 3$ & $12.6 / 32.5 / 8.9$ & $6.9 / 31.8 / 8.6$ \\
\hline $13(\mathrm{C})$ & $1 / 2 / 3$ & $74.0 / 29.7 / 29.3$ & $173.1 / 65.1 / 44.3$ \\
\hline $14(\mathrm{C})$ & $1 / 2 / 3$ & $60.5 / 88.4 / 3.1$ & $59.5 / 279.0 / 3.7$ \\
\hline
\end{tabular}

Table 2: Repeated recovery responses for the six samples; where

$\mathrm{W}=$ samples cut in the wale direction and $\mathrm{C}=$ samples cut in the course direction.

These results show that samples with conductive yarns running in the wale direction (lengthways) produced more repeatable and stable results than those in the course direction.

Following these results, a proof-of-concept elasticated knee garment was produced on the Shima Seika SES122-S vbed knitting machine. The garment was constructed using three strips of silver-coated nylon knitted into a nonconductive wool base yarn. Elastane was included in the surrounding wool base fabric, but not in the conductive sensor strips. The conductive strips were coloured to help patients with accurate donning and doffing, and detecting slip during wear. In addition, conductive stainless steel multifilament threads were embroidered to the strips to enable data collection. The garment will be tested in a follow-on study and is illustrated in Figure 5.

\section{Discussion}

Previous research examining

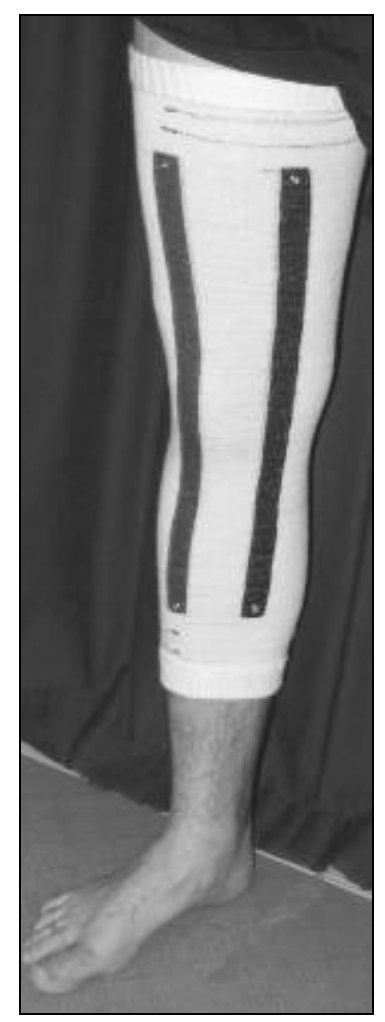

Figure 5: Proof-of-concept knee garment with coloured conductive strips, stud connectors at each end and embroidered stainless steel multifilament threads. the feasibility of using fabric based sensors for telemonitoring, rehabilitation and preventative healthcare has shown various methods to be successful (e.g. emergencyresponse [8], assisted-living and geriatric rehabilitation [9], respiratory and chronic heart failure [10], diabetes and obesity [11] and Sudden Infant Death Syndrome [12]). The MyHeart project [13] introduced the idea of 'functional clothes', i.e. garments with integrated long-term monitoring sensors, 
although MyHeart targets mainly specific cardiac well-being physiological problems.

Detecting physiological signals, such as heart-rate, with fabric-based sensors is arguably less difficult than measuring dynamic joint movement because of the repeatable response of the target. For example, the location of a heart-rate monitor is not likely to migrate in response to the movement of adjoining limb segments and heart beat is a repeatable signal that can be detected from many areas of the body.

More recently, research has begun to investigate the possibility of measuring joint movement. An intelligent knee sleeve was developed at the University of Wollongong, Australia that incorporated a sensor strip made from polypyrrole-coated nylon-lycra attached to a sports knee brace [14]. The knee sleeve was designed to provide audible feedback to athletes on detection of an appropriate level of knee flexion for a series of landing activities; the objective was to avoid ACL rupture. The sleeve does not measure dynamic knee range of movement, but has been able to detect events and provides threshold-based biofeedback as the knee bends during landing. The use of a polypyrrole coating as a conducting agent would not be suitable in garments used for monitoring purposes as it responds to changes in temperature and humidity, which you would expect to see when worn during exercise and over an extended period of time.

Our additional studies (not presented in this paper) have indicated that a tighter knit structure does not affect the conductivity of the fabric for these fibres/yarns; cover factors ranging from 0.75 to 1.74 were tested, which relate to the tightness of the knit and are representative of the cover factors that would be used in relevant commercial fabrics. Also, the difference between using wool or polyester as a surrounding base yarn was negligible, although a slight improvement was shown from samples using wool as a surrounding base yarn for recovery effects and this is why it was chosen as the base yarn for the final garment. Including elastane within the sensor area of the fabric hindered the stretching response rather than aiding the recovery response as expected. In addition, the wool-based yarns showed a greater change in resistance at the lower ranges of load $(0 g-50 \mathrm{~g})$, i.e. smaller strains, which is useful when measuring the smaller range of movement expected when assessing impairment (i.e. ACL rupture, stroke patients, etc).

\section{Conclusion}

Wearable systems provide a potentially valuable and practical solution to monitoring movement in the real environment. Problems concerning variation in sensor placement and movement over time must be addressed to improve reliability, but solutions to these problems will enable acquisition of high quality data in a real environment, providing insights into functional performance, changes associated with injury or disease, or feedback on performance.

\section{Acknowledgements}

The Authors would like to thank the Life Science Interfaces Forum at the University of Southampton for their support of this project and acknowledge the substantial contribution of AgResearch in Christchurch, New Zealand for their guidance, support, the use of the equipment and materials for this project.

\section{References}

[1] M.W.Whittle. "Gait Analysis: An Introduction", 3rd ed. Oxford: Butterworth-Heinemann, (2007).

[2] C.D.Metcalf, S.V.Notley, P.H.Chappell, J.H.Burridge, V.T.Yule. "Validation and Application of a Computational Model for Wrist and Hand Movements using Surface Markers", IEEE Trans Biomed Eng, 55, pp.1199-210, (2008).

[3] P.Cerveri, N.Lopomo, A.Pedotti, G.Ferrigno. "Derivation of Centres and Axes of Rotation for Wrist and Fingers in a Hand Kinematic Model: Methods and Reliability Results", Ann Biomed Eng, 33, pp.402-12, (2005).

[4] M.K.Rand, G.E.Stelmach, J.R.Bloedel. "Movement Accuracy Constraints in Parkinson's Disease Patients", Neuropsychologia, 38 , pp.203-12, (2000).

[5] S.Williams, R.Schmidt, C.Disselhorst-Klug, G.Rau. "An Upper Body Model for the Kinematical Analysis of the Joint Chain of the Human Arm", J Biomech, 39, pp.2419-29, (2006).

[6] H.J.Luinge, P.H.Veltink, C.T.M.Baten. "Ambulatory Measurement of Arm Orientation", J Biomech, 40, pp.78-85, (2007).

[7] P.Bonato. "Advances in Wearable Technology and Applications in Physical Medicine and Rehabilitation", Journal of NeuroEngineering and Rehabilitation, 2, pp.1-4, (2005).

[8] D.Malan, T.Fulford-Jones, M.Welsh, S.Moulton. "CodeBlue: An Ad Hoc Sensor Network Infrastructure for Emergency Medical Care", Proc Int Workshop on Wearable and Implantable Body Sensor Networks; (2004)

[9] A.Sixsmith, N.Hine, I.Neild, N.Clarke, S.Brown, P.Garner. "Monitoring the Well-Being of Older People", Topics in Geriatric Rehabilitation, 23, pp.9-22, (2007).

[10] F.S.Mair. "Does remote monitoring improve outcome in patients with chronic heart failure? ", Nature Clinical Practice Cardiovascular Medicine, 4, pp.588-9, (2007).

[11] M.Jaana, G.Pare. "Home telemonitoring of patients with diabetes: a systematic assessment of observed effects", J Eval Clin Pract, 13, pp.242-53, (2007).

[12] C.R.Baker, K.Armijo, S.Belka, M.Benhabib, V.Bhargava, N.Burkhart, et al. "Wireless sensor networks for home health care", Proc. 21st Int. Conf. on Advanced Information Networking and Applications Workshops: IEEE Computer Society; pp. 832-7,(2007)

[13] MyHeart. MyHeart Project. (2009). http://www.hitechprojects.com/euprojects/myheart/home.html.

[14] B.J.Munro, T.E.Campbell, G.G.Wallace, J.R.Steele. "The Intelligent Knee Sleeve: A Wearable Biofeedback Device", Sensors and Actuators B, 131, pp.541-7, (2008). 